\title{
Peake Responds
}

To the Editor:

First, I wish to Michael Krumper for his kind words. Krumper's point is very valid in that out-of-the body experiences and visions of an afterlife are very important elements of the near-death experience (NDE). However the very fact that these are epiphenomena of "neardeath" rather than "actual" death places them this side of the veil, as it were. All the descriptions of NDEs we have available to use are from individuals who have returned to life. In "real" death there is no return, and it is real death that is the subject of the Ferryman Thesis.

We are therefore discussing two related but different events. On one hand we have my Ferryman Thesis that attempts a scientifically based explanation of what happens to those subjects who really die; and on the other we have the subjective reports of the peculiar states of consciousness that are experienced before the "point of no return" is reached.

However unacceptable this may be to some, modern science simply cannot accommodate the reality of a consciousness existing outside the brain. For example, by what known method of vision might the disembodied consciousness process sensory inputs, that is, sight without eyes and hearing without ears? This is not to say that I doubt the veracity of these reports; indeed, many of the cases cited in the literature are very persuasive. But I have tried hard to keep my theory within the boundaries of known scientific theory. It is only by doing so that we may be able to bring this very important psychological state to the wider scientific community. 
The article is a précis of my forthcoming book, provisionally entitled Cheating the Ferryman. This will be published by Arcturus in spring of 2006. In this book of around 400 pages, I will explain in much greater detail the background to the thesis, together with a large amount of supporting material gleaned from the latest research in quantum physics, neurology, perception studies and (surprisingly enough) films such as The Matrix, Vanilla Sky, and Groundhog Day. This will be published under the name of Tony (not Anthony A.) Peake. I hope that this book will show that I have carefully reviewed much of the subjective evidence for NDEs and explained it within the framework of the Ferryman Thesis. Krumper may also be pleased to know that I do, indeed, expand upon the mechanism whereby a facsimile of the external world is generated by the brain and presented to consciousness as reality.

\section{References}

Crowe, C. (Dir.). (2001). Vanilla sky [Film]. Hollywood, CA: Paramount Motion Pictures. Ramis, H. (Dir.). (1993). Groundhog day [Film]. Hollywood, CA: Columbia Pictures.

Wachowski, A., Wachowski, L. (Dirs.) (1999). The matrix [Film]. Burbank, CA: Warner Brothers.

Anthony A. (Tony) Peake Harrogate North Yorkshire

UK

E-mail: tonyferryman@aol.com 